\title{
Accidental Hypothermia: Factors Related to a Prolonged Hospital Stay - Nationwide Observational Study in Japan -
}

Shuhei Takauji ( $\nabla$ s-takauji@asahikawa-med.ac.jp)

Asahikawa Medical University https://orcid.org/0000-0001-5794-7586

Toru Hifumi

St Luke's International Hospital

Yasuaki Saijo

Asahikawa Medical University

Shoji Yokobori

Nippon Medical School

Jun Kanda

Teikyo University Hospital

Yutaka Kondo

Juntendo University Urayasu Hospital

Kei Hayashida

North Shore University Hospital at Manhasset: North Shore University Hospital

Junya Shimazaki

Osaka University Graduate School

Takashi Moriya

Jichi Medical University Saitama Medical Center

Masaharu Yagi

Showa University School of Medicine

Junko Yamaguchi

Nihon University School of Medicine

\section{Yohei Okada}

Graduate school of Medicine, Kyoto University

\section{Yuichi Okano}

Japanese Red Cross Kumamoto Hospital

Hitoshi Kaneko

Tokyo Metropolitan Tama Medical Center

\section{Tatsuho Kobayashi}

Aizu Chuo Hospital

Motoki Fujita 
Yamaguchi University Hospital

Keiki Shimizu

Tokyo Metropolitan Tama Medical Center

\section{Hiroyuki Yokota}

Nippon Medical School

\section{Arino Yamaguchi}

Tokyo Women's Medical University

\section{Research}

Keywords: accidental hypothermia, length of hospital stay, disseminated intravascular coagulation (DIC), frailty, indoor situation

Posted Date: September 23rd, 2020

DOI: https://doi.org/10.21203/rs.3.rs-79460/v1

License: (c) (1) This work is licensed under a Creative Commons Attribution 4.0 International License. Read Full License

Version of Record: A version of this preprint was published at The American Journal of Emergency Medicine on September 1st, 2021. See the published version at https://doi.org/10.1016/j.ajem.2021.03.079. 


\section{Abstract}

Background: Accidental hypothermia $(\mathrm{AH})$ has a low frequency, and the length of hospital stay in patients with $\mathrm{AH}$ remains poorly understood. The present study explored which factors were related to long-term hospitalization among patients with AH using Japan's nationwide registry data.

Methods: The data from the Hypothermia STUDY 2018, which included patients $\geq 18$ years old with a body temperature $\leq 35^{\circ} \mathrm{C}$, were obtained from a multicenter registry for $\mathrm{AH}$ conducted at 89 institutions throughout Japan, collected from December 1, 2018, to February 28, 2019. The patients were divided into a "short-stay patients" group (within 7 days) and "long-stay patients" group (more than 7 days). A logistic regression analysis after multiple imputation was performed to obtain odds ratios (ORs) for prolonged hospitalization with age, frailty, cause of hypothermia, mechanism underlying hypothermia, temperature, $\mathrm{pH}$, potassium level, and disseminated intravascular coagulation (DIC) score as independent variables.

Results: In total, 656 patients were included in the study, of which 362 were eligible for the analysis. The median length of hospital stay was 17 days. Of the 362 patients, 265 (73.2\%) stayed in the hospital for more than 7 days. The factors associated with prolonged hospitalization were frailty (OR, $2.11 ; 95 \%$ confidence interval $[\mathrm{Cl}], 1.09-4.10 ; \mathrm{p}=0.027)$, the occurrence of indoor $(\mathrm{OR}, 3.20 ; 95 \% \mathrm{Cl}, 1.58-6.46 ; \mathrm{p}=$ 0.001), alcohol intoxication (OR, 0.17; 95\% Cl, 0.05-0.56; $\mathrm{p}=0.004), \mathrm{pH}(\mathrm{OR}, 0.07 ; 95 \% \mathrm{Cl}, 0.01-0.76 ; \mathrm{p}=$ 0.029), potassium level $(\mathrm{OR}, 1.36 ; 95 \% \mathrm{Cl}, 1.00-1.85 ; \mathrm{p}=0.048)$, and $\mathrm{DIC}$ score $(\mathrm{OR}, 1.54 ; 95 \% \mathrm{Cl}, 1.13-$ $2.10 ; p=0.006)$.

Conclusions: Frailty, indoor situation, alcohol intoxication, $\mathrm{pH}$, potassium level, and DIC score were factors contributing to prolonged hospitalization in patients with $\mathrm{AH}$. These factors can be valuable for the early detection of $\mathrm{AH}$ requiring a prolonged hospital stay.

\section{Background}

Accidental hypothermia $(\mathrm{AH})$ is defined by a body core temperature of $\angle 35^{\circ} \mathrm{C}[1,2]$. While it has a low frequency, the mortality rate is high for cases of severe hypothermia[3,4]. Previous studies regarding $\mathrm{AH}$ have shown that prognostic factors in patients with $\mathrm{AH}$ were the age, $\mathrm{pH}$, and potassium level[3-7]. However, these factors were insufficient for predicting the long-term prognosis of patients with $\mathrm{AH}$ or prescribing prophylactic measures to prevent hypothermia. In contrast, studies focusing on the length of hospital stay have proven beneficial for preventing $\mathrm{AH}$ and considering the public health regarding $\mathrm{AH}$. For instance, shortening hospitalization can increase the bed turnover rate, thereby reducing medical costs. However, few studies have investigated which factors are associated with the length of hospital stay [8].

The characteristics of patients with $\mathrm{AH}$ in Japan include an older age, high rate of occurring indoors, and high mortality rate [9] [10]. Japan is the most rapidly aging society in the world, so we believe that analyzing the $\mathrm{AH}$ registry in Japan will meaningfully influence the situation in other countries that are also experiencing the aging of their societies. 
The present study investigated which factors are associated with long-term hospitalization in patients with AH using Japan's nationwide registry data of hypothermia.

\section{Material And Methods}

\section{Study design and setting}

We performed a prospective, observational, multi-center registry of hypothermia: the Hypothermia STUDY 2018. This study was conducted from December 1, 2018, to February 28, 2019, among a consortium of 89 academic and community medical centers from different geographic regions across Japan. The study was approved by the institutional review board of each hospital listed in the acknowledgements, and the requirement for informed consent was waived due to the observational nature of the study.

\section{Patient selection and data collection}

The present study included consecutive patients whose body temperature measured by emergency medical services (EMS) or at emergency department was less than $35^{\circ} \mathrm{C}$. Patients younger than 18 years old were excluded. The following data were collected: age, sex, any pre-existing conditions, activities of daily living, lifestyle, mechanism underlying hypothermia (acute medical illness, trauma [subimmersion, distress], alcohol intoxication, others [including drugs]), cause of hypothermia, Charlson comorbidity index, Glasgow coma scale (GCS), Sequential Organ Failure Assessment (SOFA) score [11], disseminated intravascular coagulation (DIC) score [12], laboratory data, temperature, dysrhythmias, cardiac arrest during pre-hospital, venous-arterial extracorporeal membrane oxygenation (V-A ECMO) rewarming, intubation, hospital periods, survival, and Cerebral Performance Category (CPC) score at 30 days after admission.

Acute medical illnesses were as follows: cerebrovascular disease, cardiac disease, infectious disease, undernutrition, epilepsy, renal disease, endocrine disease, gastrointestinal disease. The clinical frailty scale (CFS) score was determined using the activities of daily living and pre-existing conditions, as described previously [13]. Patients were defined as frail if they had a CFS score of $\geq 5$ before hospital admission. Temperature was recorded as the core temperature from the rectum, urinary bladder, or esophagus if available; otherwise, the peripheral temperature from the axilla or ear was noted.

Hypothermia was classified according to the temperature as mild $\left(35-32^{\circ} \mathrm{C}\right)$, moderate $\left(32-28^{\circ} \mathrm{C}\right)$, of severe $\left(<28^{\circ} \mathrm{C}\right)$.

The laboratory data included the $\mathrm{pH}$, potassium level, platelet count, and CPK level at the emergency department. The $\mathrm{pH}$ value in principle was evaluated by an arterial blood gas analysis, and the $\mathrm{pH}$ measured using the venous blood gas was adjusted as described in a previous study [14]. Complications during hospitalization were recorded and classified as pneumonia, pancreatitis, or other. Pneumonia was defined as an obvious shadow on chest radiography or computed tomography (CT). Pancreatitis was defined as cases meeting at least two of the following conditions: 1) abdominal pain, 2) elevation of pancreatic enzyme levels in the blood, and 3) edema of the pancreas or peripancreatic effusion on 
ultrasound/CT. In the present study, patients were excluded from the analysis if they were 30-day nonsurvivors, lacked a hospital stay, or had an unknown length of hospital stay or an unknown body temperature, as these patients had potential biases.

Previous studies showed that the median length of hospital stay in patients with AH was 4-9 days [10] [4] [8]. We therefore divided the patients with AH into 2 groups: the "short-stay patients" group ( $\leq 7$ days) and "long-stay patients" group (>7 days).

\section{Data analyses}

Data are expressed as the number (\%) or median (interquartile range), as appropriate. Intergroup comparisons were made using Fisher's exact test for categorical data and the Mann-Whitney $\mathrm{U}$ test for continuous data. For a further evaluation, we conducted multivariate logistic regression analyses to control for the potentially confounding roles of age, frailty, cause of hypothermia, mechanism underlying hypothermia, temperature, $\mathrm{pH}$, potassium, and DIC score. These potential confounders were selected based on a previous study regarding $\mathrm{AH}$ [8] or the consideration of clinically significant variables. Furthermore, a multiple linear regression analysis including similar variables was performed. Missing data were managed with multiple imputation by chained equations $[15,16]$. The variables included in the imputation model were those from the logistic regression analysis. Twenty-five dataset were imputed with 10 iterations each. Multivariate logistic regression and multiple liner regression analyses were applied to the 25 imputed datasets, and final estimates were obtained by averaging the 25 estimates according to Rubin's rules. Furthermore, a complete data set was used for the sensitive analysis. All tests were two-sided with $P$ values of less than 0.05 considered statistically significant.

Statistical analyses were performed with the EZR software program (Saitama Medical Center, Jichi Medical University, Saitama, Japan), a graphical user interface for R software. Multiple imputation was performed using mice package in the $\mathrm{R}$ software program, version 4.0.1 (R Foundation for Statistical Computing, Vienna, Austria).

\section{Results}

Of the 656 patients with hypothermia included in the Hypothermia STUDY 2018, 294 were excluded from the present study because of death within 30 days $(N=160)$, non-hospital stay $(N=110)$, unknown length of hospital stay $(\mathrm{N}=21)$, or others, including an unknown temperature $(\mathrm{N}=3)$. The remaining 362 patients were eligible for the present analysis. The patient flow diagram is shown in Fig. 1. Depending on the length of hospital stay, the 362 patients were divided into the "short-stay patients" group ( $N=97)$ and "long-stay patients" group ( $\mathrm{N}=265)$. The overall mortality rate within 30 days was 160 among 656 patients (24.4\%). Among the remaining 362 patients, 265 (73.2\%) stayed in the hospital for more than 7 days.

\section{Baseline characteristics of the study population}


Table 1 shows the baseline characteristics of the study population and a comparison of the clinical characteristics between the "short-stay patients" and "long-stay patients" groups. The median patient age was 78 years old, and $75.1 \%$ of AH cases occurred indoors. The age, SOFA score, and DIC score were higher in the "long-stay patients" group than in the "short-stay patients" group. There was a significant difference in the CFS score, cause of hypothermia, and mechanism of hypothermia between the "shortstay patients" and "long-stay patients" groups. In the "long-stay patients" group, the rate of occurrence indoors was higher than that in the "short-stay patients" group. Regarding the cause of hypothermia, acute illness was the predominant cause in the "long-stay patients" group, whereas the proportion of cases caused by alcohol intoxication was higher in "short-stay patients" group than in the "long-stay patients" group.

\section{Clinical and laboratory data}

The clinical and laboratory data are presented in Table 2. There were no significant differences in the severity grade of temperature, GCS, blood pressure, heart rate, respiratory rate, platelet level, or rate of intubation between the "short-stay patients" and "long-stay patients" groups. However, the pH values were significantly lower and the potassium and CPK levels higher in the "long-stay patient" group than in the "short-stay patient" group. In addition, the "long-stay patient" group showed a significantly higher incidence of arrhythmia than the "short-stay patient" group. A total of 222 (61.3\%) patients were admitted to the intensive-care unit (ICU), although there was no significant difference in the rate of ICU admission between the groups.

\section{Complications, neurological score, and hospital length of stay}

There was no significant difference in the incidence of complications between the "short-stay patients" and "long-stay patients" groups (Table 3). However, at the neurological assessment, the "long-stay patients" group showed a higher rate of worsened neurological score (CPC 3-5) at 30 days after admission than the "short-stay patients" group, while the "short-stay patients" group showed a significantly higher rate of patients with a favorable neurological outcome (CPC 1-2) than the "long-stay patients" group. The median length of ICU stay was 4 days, and the median length of hospital stay was 17 days for the 362 total patients. Additional file 1 shows the distribution of the hospital stay duration.

\section{Multivariate logistic regression analyses}

Table 4 shows that the factors associated with the length of hospital stay, based on a multivariate logistic regression analysis after multiple imputation, were frailty (odds ratio [OR], $2.11 ; 95 \%$ confidence interval $[\mathrm{Cl}$, 1.09- 4.10; $\mathrm{p}=0.027$ ), indoor occurrence (OR, 3.20;95\% $\mathrm{Cl}, 1.58-6.46 ; \mathrm{p}=0.001)$, mechanism underlying hypothermia (alcohol intoxication) $(\mathrm{OR}, 0.17 ; 95 \% \mathrm{Cl}, 0.05-0.56 ; \mathrm{p}=0.004), \mathrm{pH}(\mathrm{OR}, 0.07 ; 95 \%$ $\mathrm{Cl}, 0.01-0.76 ; \mathrm{p}=0.029)$, potassium levels $(\mathrm{OR}, 1.36 ; 95 \% \mathrm{Cl}, 1.00-1.85 ; \mathrm{p}=0.048)$, and the DIC score (OR, $1.54 ; 95 \% \mathrm{Cl}, 1.13-2.10 ; \mathrm{p}=0.006)$. In the sensitivity analysis, $\mathrm{pH}(\mathrm{OR}, 0.10 ; 95 \% \mathrm{Cl}, 0.01-1.11, \mathrm{p}=0.061)$ was not significantly associated with the length of hospital stay, but the result was close to significance, 
and the sensitivity analysis showed similar results to the analysis after multiple imputation. Thus, the results of the analysis after multiple imputation were considered robust.

\section{Multiple liner regression analyses}

Table 5 shows the correlation between variables and the length of hospital stay, based on a multiple liner regression analysis after multiple imputation. Indoor occurrence $(\beta=7.19 ; 95 \% \mathrm{Cl}, 1.14-13.24, P=0.020)$, mechanism underlying hypothermia (alcohol intoxication) $(\beta=-10.82 ; 95 \% \mathrm{Cl},-20.92-0.71, \mathrm{P}=0.036$ ), and the DIC score $(\beta=2.84 ; 95 \% \mathrm{Cl}, 0.41-5.28, \mathrm{P}=0.022)$ were significantly correlated with the length of hospital stay. In the sensitivity analysis, alcohol intoxication $(\beta=-8.95 ; 95 \% \mathrm{Cl},-20.82-2.91, p=0.139)$ was not significantly associated with the length of hospital stay, but the result was close to significance, so the interpretation of results did not make much difference. Thus, the results of the analysis after multiple imputation were considered robust.

\section{Discussion}

The present nationwide study showed that a total of $75.1 \%$ of patients with $\mathrm{AH}$ developed $\mathrm{AH}$ indoors. $\mathrm{A}$ total of $73.2 \%$ of patients with $\mathrm{AH}$ stayed in hospitals for more than 7 days. The median length of hospital stay was 17 days. The rate of complications was low, there was no association between complications and the length of hospital stay. The factors related to long-term hospitalization were frailty, indoor occurrence, alcohol intoxication, $\mathrm{pH}$, potassium levels, and the DIC score.

Among these factors related to a prolonged hospital stay, the $\mathrm{pH}$, potassium levels, and DIC score were not preventable, while frailty and an indoor occurrence were potentially preventable with intervention. Previous studies have shown many patients with $\mathrm{AH}$ in urban settings develop AH indoors [9] [10], which was in agreement with the present findings. In addition, the patients who develop AH indoors have a higher death rate and longer hospital stay because of their tendency to have an advanced age [17] [10]. However, of note, the present study showed that the factors associated with the length of hospital stay were not just the age but the frailty. Recently, frailty, which is highly prevalent in older individuals and confers a high risk of falls, disability, hospitalization, and mortality [18], has also been noted in critically ill patients [19] [20]. To our knowledge, limited data exist regarding the relationship between $\mathrm{AH}$ and frailty. The present findings are of critical importance. Clinically, the risk factors of frailty and an indoor occurrence may be useful for the early detection of AH patients likely to require a prolonged hospital stay. In the future, preventing frailty and maintaining adequate activities of daily living may help suppress the occurrence of $\mathrm{AH}$ and reduce the length of hospital stay. This approach is certain to have an incredible impact on the aging populations of Japan as well as other industrialized countries.

In the present study, alcohol intoxication, $\mathrm{pH}$, potassium levels, and the DIC score were shown to be associated with length of hospital stay. In general, the DIC score is increased by sepsis and organ failure. Accordingly, AH patients complicated by such issues may have a significantly prolonged hospital stay. Alcohol intoxication was conversely associated with a short hospital stay. We speculate that these patients had acute alcohol intoxication, which resulted in an early discharge from the hospital after 
rewarming and awakening. However, a previous study showed that a lower core temperature, lower degree of consciousness, and lower platelet count were associated with a prolonged hospital stay, although these factors were not found to be associated in the present study. Several reasons may explain this discrepancy. First, the previous study differed from the present study with regard to the patient background. Previous studies regarding AH patients from Europe and North Europe showed that these patients were mostly healthy, younger individuals, and AH occurred outdoors, such as in cases of avalanche or submersion in freezing water [3,21,22], resulting in an early discharge from the hospital. In contrast, the patients in the present study were older individuals with underlying diseases, and $\mathrm{AH}$ tended to occur indoors. These differences may affect the factors associated with the hospital stay. Second, the previous study was performed at a single institution and extracted from a univariate analysis, so potential confounders were not considered for adjustment. The present study was a multicenter, nationwide study associated with $\mathrm{AH}$ in Japan and involved a multivariate analysis of credible data.

The present study had several limitations. First, the length of hospitalization is influenced by the social environment and medical care system. Therefore, it may be not appropriate to compare the results of this study with those from other countries. Second, this registry did not include data on the CFS score, and instead, the CFS score was evaluated using the activities of daily living and pre-existing conditions. As a result, the frailty not have been accurately classified. Finally, although we adjusted for variables, the possibility of residual confounding factors cannot be avoided.

\section{Conclusions}

This study found, that among patients with $\mathrm{AH}$, three-quarters needed to be hospitalized for more than 7 days. The factors related to a prolonged hospital stay were frailty, indoor occurrence, $\mathrm{pH}$, potassium levels, and the DIC score. Conversely, alcohol intoxication was associated with a short hospital stay. Taken together, these findings suggest that reducing frailty and maintaining adequate activities of daily living may help reduce the length of hospital stay in patients with $\mathrm{AH}$. This is certain to influence the outcomes of aging populations in Japan as well as other industrialized countries.

\section{Abbreviations}

AH: Accidental hypothermia, ORs: odds ratios, Cl: confidence interval, DIC: disseminated intravascular coagulation, EMS: emergency medical services, GCS: Glasgow coma scale, SOFA: Sequential Organ Failure Assessment, V-A ECMO: venous-arterial extracorporeal membrane oxygenation, CPC: Cerebral Performance Category, CFS: clinical frailty scale, CT: computed tomography, CPA: cardiopulmonary arrest, ECG: electrocardiogram, ED: emergency department, VF: ventricular fibrillation, PEA: pulseless electrical activity, ICU: intensive-care unit

\section{Declarations}

Acknowledgements: 


\section{List of hospitals participating in the present study}

Aizawa Hospital

Akita Red Cross Hospital

Asahikawa City Hospital

Asahikawa Medical University Hospital

Center Hospital of the National Center for Global Health and Medicine

Daiyukai General Hospital

Dokkyo Medical University Nikko Medical Center

Dokkyo Medical University Saitama Medical Center

Esashi Hospital

Fujieda Municipal General Hospital

Fujisawa City Hospital

Fukui Prefectual Hospital

Funabashi Municipal Medical Center

Gifu Prefectual General Medical Center

Gifu University Hospital

Hamamatsu Medical Center

Hidaka Tokushukai Hospital

Hokkaido Medical Center

Hyogo Emergency Medical Center

Hyogo Prefectual Nishinomiya Hospital

Ina Central Hospital

Ise Red Cross Hospital

Ishikawa Prefectual Central Hospital 
Ishinomaki Red Cross Hospital

Iwata City Hospital

Iwate Prefectual Central Hospital

Japanese Red Cross Society Kyoto Daiichi Hospital

Juntendo University Nerima Hospital

Juntendo University Urayasu Hospital

Kagawa University Hospital

Kansai Medical University Hospital

Kasugai Municipal Hospital

Kawaguchi Municipal Medical Center

Kawasaki Municipal Hospital

Kimitsu Chuo Hospital

Kumamoto Red Cross Hospital

Kyorin University Hospital

Kyoto University Hospital

Mie Prefectual Genaral Medical Center

Miyazaki Prefectual Nobeoka Hospital

Nagano Red Cross Hospital

Nagasaki University Hospital

Nagoya Ekisaikai Hospital

Nagoya University Hospital

Narita Red Cross Hospital

Nasu Red Cross Hospital

National Defense Medical College Hospital 
National Hospital Organization Mito Medical Center

National Hospital Organization Nagoya Medical Center

National Hospital Organization Osaka National Hospital

Nayoro City General Hospital

Nihon University Hospital

Nihon University Itabashi Hospital

Nihonkai General Hospital

Niigata University Medical \& Dental Hospital

Nippon Medical School Hospital

Nippon Medical School Tamanagayama Hospital

Oita University Hospital

Ome Municipal Central Hospital

Osaka City General Hospital

Ota Memorial Hospital

Rinku General Medical Center

Saiseikai Shiga Hospital

Saiseikai Utsunomiya Hospital

Sapporo City General Hospital

Seirei Hamamatsu General Hospital

Seirei Mikatahara General Hospital

Shinshu University Hospital

Shonan Kamakura General Hospital

St.Mary's Hospital

Steel Memorial Hirohata Hospital 
Takasaki General Medical Center

Teikyo University Hospital

Teine Keijinkai Hospital

Tenshi Hospital

Toho University Omori Medical Center

Tokushima Prefectual Miyoshi Hospital

Tokuyama Central Hospital

Tokyo Metropolitan Tama Medical Center

Tosei General Hospital

Toyama University Hospital

Tsuyama Chuo Hospital

University of Tokyo Hospital

University of Yamanashi Hospital

Yamagata University Hospital

Yamaguchi University Hospital

Yamanashi Prefectual Central Hospital

Yokkaichi Municipal Hospital

Yokohama Minami Kyosai Hospital

\section{Authors' contributions:}

ST and JK contributed to the conception and design of this analysis. ST wrote the manuscript. TH, SY, $\mathrm{YK}, \mathrm{KH}$, and JS supervised the work. YS provided statistical advice on the study design and the analyzed data. TM, MY, JY, YO, YO, HK, TK, MF, KS, HY, and AY contributed to the interpretation of the results. All authors read and approved the final manuscript.

\section{Funding:}

None 
Availability of data and materials:

No data is available

Ethics approval and consent to participate:

The institutional review board of each hospital listed in the acknowledgements approved the study, and the requirement for informed consent was waived due to the observational nature of the study.

Consent for publication:

Not applicable

Competing interests:

The authors declare that they have no competing interests.

\section{References}

1. Brown DJ, Brugger H, Boyd J, Paal P: Accidental hypothermia. The New England journal of medicine 2012, 367(20):1930-1938.

2. Jarosz A, Kosinski S, Darocha T, Paal P, Galazkowski R, Hymczak H, Drwila R: Problems and Pitfalls of Qualification for Extracorporeal Rewarming in Severe Accidental Hypothermia. J Cardiothorac Vasc Anesth 2016, 30(6):1693-1697.

3. Silfvast T, Pettilä V: Outcome from severe accidental hypothermia in Southern Finland-a 10-year review. Resuscitation 2003, 59(3):285-290.

4. van der Ploeg GJ, Goslings JC, Walpoth BH, Bierens JJ: Accidental hypothermia: rewarming treatments, complications and outcomes from one university medical centre. Resuscitation 2010, 81(11):1550-1555.

5. Elbaz G, Etzion O, Delgado J, Porath A, Talmor D, Novack V: Hypothermia in a desert climate: severity score and mortality prediction. Am J Emerg Med 2008, 26(6):683-688.

6. Schaller MD, Fischer AP, Perret $\mathrm{CH}$ : Hyperkalemia. A prognostic factor during acute severe hypothermia. Jama 1990, 264(14):1842-1845.

7. Okada Y, Matsuyama T, Morita S, Ehara N, Miyamae N, Jo T, Sumida Y, Okada N, Kitamura T, liduka R: Prognostic factors for patients with accidental hypothermia: A multi-institutional retrospective cohort study. Am J Emerg Med 2019, 37(4):565-570.

8. Pirnes J, Ala-Kokko T: Accidental hypothermia: factors related to long-term hospitalization. A retrospective study from northern Finland. Internal and emergency medicine 2017, 12(8):1225-1233.

9. Yokota $\mathrm{H}$ : The clinical characteristics of hypothermic patients in the winter of Japan-the final report of hypothermia STUDY 2011. Journal of Japanese Association for Acute Medicine 2013, 24:377389. 
10. Megarbane B, Axler O, Chary I, Pompier R, Brivet FG: Hypothermia with indoor occurrence is associated with a worse outcome. Intensive Care Med 2000, 26(12):1843-1849.

11. Vincent JL, de Mendonça A, Cantraine F, Moreno R, Takala J, Suter PM, Sprung CL, Colardyn F, Blecher S: Use of the SOFA score to assess the incidence of organ dysfunction/failure in intensive care units: results of a multicenter, prospective study. Working group on "sepsis-related problems" of the European Society of Intensive Care Medicine. Critical care medicine 1998, 26(11):1793-1800.

12. Gando S, Iba T, Eguchi Y, Ohtomo Y, Okamoto K, Koseki K, Mayumi T, Murata A, Ikeda T, Ishikura H et al: A multicenter, prospective validation of disseminated intravascular coagulation diagnostic criteria for critically ill patients: comparing current criteria. Critical care medicine 2006, 34(3):625-631.

13. Rockwood K, Song X, MacKnight C, Bergman H, Hogan DB, McDowell I, Mitnitski A: A global clinical measure of fitness and frailty in elderly people. CMAJ 2005, 173(5):489-495.

14. Bloom BM, Grundlingh J, Bestwick JP, Harris T: The role of venous blood gas in the emergency department: a systematic review and meta-analysis. Eur J Emerg Med 2014, 21(2):81-88.

15. Chevret S, Seaman S, Resche-Rigon M: Multiple imputation: a mature approach to dealing with missing data. Intensive Care Med 2015, 41(2):348-350.

16. White IR, Royston P, Wood AM: Multiple imputation using chained equations: Issues and guidance for practice. Stat Med 2011, 30(4):377-399.

17. Bierens JJ, Uitslager R, Swenne-van Ingen MM, van Stiphout WA, Knape JT: Accidental hypothermia: incidence, risk factors and clinical course of patients admitted to hospital. Eur J Emerg Med 1995, 2(1):38-46.

18. Fried LP, Tangen CM, Walston J, Newman AB, Hirsch C, Gottdiener J, Seeman T, Tracy R, Kop WJ, Burke G et al: Frailty in older adults: evidence for a phenotype. J Gerontol A Biol Sci Med Sci 2001, 56(3):M146-156.

19. Silva-Obregon JA, Quintana-Diaz M, Saboya-Sanchez S, Marian-Crespo C, Romera-Ortega MA, Chamorro-Jambrina C, Estrella-Alonso A, Andres-Esteban EM: Frailty as a predictor of short- and long-term mortality in critically ill older medical patients. Journal of critical care 2020, 55:79-85.

20. Muscedere J, Waters B, Varambally A, Bagshaw SM, Boyd JG, Maslove D, Sibley S, Rockwood K: The impact of frailty on intensive care unit outcomes: a systematic review and meta-analysis. Intensive Care Med 2017, 43(8):1105-1122.

21. Hilmo J, Naesheim T, Gilbert M: "Nobody is dead until warm and dead": prolonged resuscitation is warranted in arrested hypothermic victims also in remote areas-a retrospective study from northern Norway. Resuscitation 2014, 85(9):1204-1211.

22. Debaty G, Moustapha I, Bouzat P, Maignan M, Blancher M, Rallo A, Brun J, Chavanon O, Danel V, Carpentier F et al: Outcome after severe accidental hypothermia in the French Alps: A 10-year review. Resuscitation 2015, 93:118-123.

\section{Tables}


Table 1.

Characteristics of patients with hypothermia

\begin{tabular}{|c|c|c|c|c|c|}
\hline & $\begin{array}{l}\text { All } \\
\text { patients }\end{array}$ & Missing & $\begin{array}{l}\text { Short-stay } \\
\text { patients }\end{array}$ & $\begin{array}{l}\text { Long-stay } \\
\text { patients }\end{array}$ & $\begin{array}{l}\mathrm{p}- \\
\text { value }\end{array}$ \\
\hline & $n=362$ & $\mathrm{n},(\%)$ & $n=97$ & $\mathrm{n}=265$ & \\
\hline Age, years & $\begin{array}{l}78(68- \\
87)\end{array}$ & 0 & $75(62-86)$ & $79(69-87)$ & 0.035 \\
\hline Males & $\begin{array}{l}197 \\
(54.4 \%)\end{array}$ & 0 & $51(52.6 \%)$ & $146(55.1 \%)$ & 0.721 \\
\hline Charlson comorbidity index & $1(0-1)$ & 0 & $1(0-1)$ & $1(0-2)$ & 0.341 \\
\hline \multicolumn{6}{|l|}{ Severity } \\
\hline SOFA total & $4(2-7)$ & $29(8.0)$ & $3(2-5)$ & $5(3-7)$ & $\begin{array}{l}< \\
0.001\end{array}$ \\
\hline DIC score & $2(1-3)$ & $1(0.0)$ & $2(1-2)$ & $2(1-3)$ & $\dot{0} 001$ \\
\hline Clinical Frailty Scale score & & $11(3.0)$ & & & 0.009 \\
\hline $1:$ very fit & $\begin{array}{l}93 \\
(25.7 \%)\end{array}$ & & $32(34.0 \%)$ & $61(23.7 \%)$ & \\
\hline 2: well & $\begin{array}{l}115 \\
(31.8 \%)\end{array}$ & & $30(31.9 \%)$ & $85(33.1 \%)$ & \\
\hline $\begin{array}{l}\text { 3: well with treated comorbid } \\
\text { disease }\end{array}$ & $21(5.8 \%)$ & & $6(6.4 \%)$ & $15(5.8 \%)$ & \\
\hline 4: apparently vulnerable & $\begin{array}{l}45 \\
(12.4 \%)\end{array}$ & & $2(2.1 \%)$ & $43(16.7 \%)$ & \\
\hline 5: mildly frail & $\begin{array}{l}47 \\
(13.0 \%)\end{array}$ & & $17(18.1 \%)$ & $30(11.7 \%)$ & \\
\hline 6: moderately frail & $13(3.6 \%)$ & & $4(4.3 \%)$ & $9(3.5 \%)$ & \\
\hline 7: severely frail & $17(4.7 \%)$ & & $3(3.2 \%)$ & $14(5.4 \%)$ & \\
\hline Lifestyle & & $8(2.2)$ & & & 0.866 \\
\hline Living alone & $\begin{array}{l}128 \\
(36.2 \%)\end{array}$ & & $30(32.3 \%)$ & $98(37.5 \%)$ & \\
\hline Not living alone & $\begin{array}{l}210 \\
(59.3 \%)\end{array}$ & & $59(63.4 \%)$ & $151(57.9 \%)$ & \\
\hline Homelessness & $1(0.3 \%)$ & & $0(0.0 \%)$ & $1(0.4 \%)$ & \\
\hline Nursing home & $10(2.8 \%)$ & & $3(3.2 \%)$ & $7(2.7 \%)$ & \\
\hline Unknown & $5(1.4 \%)$ & & $1(1.1 \%)$ & $4(1.5 \%)$ & \\
\hline
\end{tabular}

Page $15 / 21$ 


\begin{tabular}{|c|c|c|c|c|}
\hline \multicolumn{2}{|l|}{ Location } & \multicolumn{2}{|c|}{$16(4.4)$} & \multirow[t]{2}{*}{$<.001$} \\
\hline Outdoor & $\begin{array}{l}86 \\
(24.9 \%)\end{array}$ & $40(42.6 \%)$ & $46(18.3 \%)$ & \\
\hline Indoor & $\begin{array}{l}260 \\
(75.1 \%)\end{array}$ & $54(57.4 \%)$ & $206(81.7 \%)$ & \\
\hline $\begin{array}{l}\text { Mechanism underlying } \\
\text { hypothermia }\end{array}$ & & & & $\dot{0.001}$ \\
\hline Acute medical illness & $\begin{array}{l}192 \\
(53.0 \%)\end{array}$ & $35(39.8 \%)$ & $157(62.1 \%)$ & \\
\hline $\begin{array}{l}\text { Trauma, Subimmersion, and } \\
\text { distress }\end{array}$ & $\begin{array}{l}53 \\
(14.6 \%)\end{array}$ & $15(17.0 \%)$ & $38(15.0 \%)$ & \\
\hline Alcohol intoxication & $22(6.1 \%)$ & $16(18.2 \%)$ & $6(2.4 \%)$ & \\
\hline Others (Unknown, drug) & $\begin{array}{l}74 \\
(20.4 \%)\end{array}$ & $22(25.0 \%)$ & $52(20.6 \%)$ & \\
\hline
\end{tabular}


Table 2 .

Clinical and laboratory data of patients with hypothermia

\begin{tabular}{|c|c|c|c|c|c|}
\hline & All patients & Missing & $\begin{array}{l}\text { Short-stay } \\
\text { patients }\end{array}$ & $\begin{array}{l}\text { Long-stay } \\
\text { patients }\end{array}$ & $\begin{array}{l}p- \\
\text { value }\end{array}$ \\
\hline & $n=362$ & $\mathrm{n},(\%)$ & $n=97$ & $\mathrm{n}=265$ & \\
\hline Temperature & $\begin{array}{l}30.8(28.5- \\
33.2)\end{array}$ & 0 & $31.8(29.4-33.7)$ & $30.6(28.2-33.1)$ & 0.036 \\
\hline $\begin{array}{l}\text { Mild } \\
\left(35-32{ }^{\circ} \mathrm{C}\right)\end{array}$ & $143(39.5 \%)$ & & 47 (48.5\%) & $96(36.2 \%)$ & 0.089 \\
\hline $\begin{array}{l}\text { Moderate } \\
\left(32-28^{\circ} \mathrm{C}\right)\end{array}$ & $144(39.8 \%)$ & & $35(36.1 \%)$ & $109(41.1 \%)$ & \\
\hline $\begin{array}{l}\text { Severe } \\
\left(<28^{\circ} \mathrm{C}\right)\end{array}$ & 75 (20.7\%) & & 15 (15.5\%) & $60(22.6 \%)$ & \\
\hline GCS & $11(9-14)$ & $14(3.9)$ & $13(9-14)$ & $11(8-14)$ & 0.086 \\
\hline $\begin{array}{l}\text { Systolic BP } \\
(\mathrm{mmHg})\end{array}$ & $120(96-146)$ & $25(6.9)$ & $126(98-153)$ & $119(95-142)$ & 0.197 \\
\hline $\begin{array}{l}\text { Diastolic BP } \\
(\mathrm{mmHg})\end{array}$ & $71(55-89)$ & $30(8.3)$ & $76(60-90)$ & $70(52-87)$ & 0.115 \\
\hline Heart rate & $70(54-91)$ & $7(1.9)$ & $73(56-93)$ & $70(53-90)$ & 0.474 \\
\hline Respiratory rate & $18(15-22)$ & $27(7.5)$ & $17(14-20)$ & $18(15-22)$ & 0.106 \\
\hline $\mathrm{pH}$ & $\begin{array}{l}7.32(7.21- \\
7.37)\end{array}$ & $\begin{array}{l}48 \\
(13.3)\end{array}$ & $7.34(7.27-7.39)$ & 7.31 (7.21-7.37) & 0.018 \\
\hline $\begin{array}{l}\text { Potassium } \\
(\mathrm{mEq} / \mathrm{L})\end{array}$ & $4.2(3.6-4.9)$ & $7(1.9)$ & $3.9(3.5-4.4)$ & $4.3(3.7-5.0)$ & 0.001 \\
\hline Plt $\left(\times 10^{4} / \mu \mathrm{L}\right)$ & $\begin{array}{l}18.7(13.1- \\
25.3)\end{array}$ & $7(1.9)$ & $19.5(14.1-25.5)$ & $18.4(12.5-24.8)$ & 0.328 \\
\hline CPK (U/L) & $\begin{array}{l}378(157- \\
1210)\end{array}$ & $26(7.2)$ & $219(118-593)$ & $459(180-1409)$ & $\begin{array}{l}< \\
0.001\end{array}$ \\
\hline ECG at ED & & $19(5.3)$ & & & 0.001 \\
\hline Normal & $147(40.6 \%)$ & & $54(59.3 \%)$ & $93(36.9 \%)$ & \\
\hline Abnormal & $196(54.1 \%)$ & & $37(40.7 \%)$ & $159(63.1 \%)$ & \\
\hline CPA & 13 & 0 & 0 & 13 & 0.024 \\
\hline Intubation & 47 & $20(5.5)$ & 8 & 39 & 0.153 \\
\hline V-A ECMO & 9 & 0 & 0 & 9 & 0.120 \\
\hline Admitted to ICU & $222(61.3 \%)$ & 0 & $52(53.6 \%)$ & $170(64.2 \%)$ & 0.088 \\
\hline
\end{tabular}


GCS, Glasgow Coma Scale; ECG, electrocardiogram; ED, emergency department; CPA, cardiopulmonary arrest; ECMO, extracorporeal membrane oxygenation

The data are expressed as the number (\%) or median (interquartile range).

Table 3.

Complications, neurological score and hospital length of stay

\begin{tabular}{|c|c|c|c|c|}
\hline & All patients & Short-stay patients & Long-stay patients & $\mathrm{p}$-value \\
\hline & $n=362$ & $\mathrm{n}=97$ & $\mathrm{n}=265$ & \\
\hline Length of stay in the ICU & $4(2-7)$ & $2(2-3)$ & $5(3-9)$ & $<0.001$ \\
\hline Length of stay in the hospital & $17(7-32)$ & $4(2-6)$ & $24(14-38)$ & $<0.001$ \\
\hline $\mathrm{CPC}$ at 30 days & & & & 0.008 \\
\hline $\operatorname{good}(1-2)$ & 167 & 45 & 122 & \\
\hline poor $(3-5)$ & 72 & 9 & 67 & \\
\hline Complications & & & & 0.768 \\
\hline None & 357 & 97 & 260 & \\
\hline Pneumonia & 1 & 0 & 1 & \\
\hline Pancreatitis & 1 & 0 & 1 & \\
\hline Other & 3 & 0 & 3 & \\
\hline Complications of arrhythmia & & & & 1.000 \\
\hline None & 354 & 96 & 258 & \\
\hline VF & 2 & 0 & 2 & \\
\hline PEA & 1 & 0 & 1 & \\
\hline Bradycardia & 4 & 1 & 3 & \\
\hline Other & 1 & 0 & 1 & \\
\hline
\end{tabular}


Table 4.

Results of a multivariate logistic regression analysis for factors associated with the length of hospital stay

\begin{tabular}{|c|c|c|c|c|c|c|}
\hline \multirow[t]{2}{*}{ Variables } & \multicolumn{3}{|c|}{$\begin{array}{l}\text { Model without imputation }(\mathrm{N}= \\
281)\end{array}$} & \multicolumn{3}{|c|}{$\begin{array}{l}\text { Model with imputation }(\mathrm{N}= \\
362)\end{array}$} \\
\hline & OR & $95 \% \mathrm{Cl}$ & $\begin{array}{l}\mathrm{P}- \\
\text { value }\end{array}$ & OR & $95 \% \mathrm{Cl}$ & $\begin{array}{l}\mathrm{P} \text { - } \\
\text { value }\end{array}$ \\
\hline Age, years & 1.02 & $\begin{array}{l}0.99- \\
1.05\end{array}$ & 0.069 & 1.02 & $\begin{array}{l}0.99- \\
1.04\end{array}$ & 0.103 \\
\hline Frailty (CFS $\geq 5$ ) & 2.59 & $\begin{array}{l}1.19- \\
5.63\end{array}$ & 0.017 & 2.11 & $\begin{array}{l}1.09- \\
4.10\end{array}$ & 0.027 \\
\hline \multicolumn{7}{|l|}{ Location } \\
\hline Outdoor & Reference & & - & Reference & & - \\
\hline Indoor & 3.57 & $\begin{array}{l}1.55- \\
8.23\end{array}$ & 0.003 & 3.20 & $\begin{array}{l}1.58- \\
6.46\end{array}$ & 0.001 \\
\hline \multicolumn{7}{|l|}{$\begin{array}{l}\text { Mechanism causing } \\
\text { hypothermia }\end{array}$} \\
\hline Acute medical illness & Reference & & - & Reference & & - \\
\hline $\begin{array}{l}\text { Trauma, Subimmersion, and } \\
\text { distress }\end{array}$ & 0.88 & $\begin{array}{l}0.32- \\
2.45\end{array}$ & 0.804 & 0.95 & $\begin{array}{l}0.40- \\
2.28\end{array}$ & 0.913 \\
\hline Alcohol intoxication & 0.20 & $\begin{array}{l}0.05- \\
0.73\end{array}$ & 0.015 & 0.17 & $\begin{array}{l}0.05- \\
0.56\end{array}$ & 0.004 \\
\hline Others (Unknown, drug) & 0.72 & $\begin{array}{l}0.34- \\
1.55\end{array}$ & 0.408 & 0.68 & $\begin{array}{l}0.34- \\
1.34\end{array}$ & 0.263 \\
\hline Temperature (per $1^{\circ} \mathrm{C}$ ) & 0.97 & $\begin{array}{l}0.87- \\
1.07\end{array}$ & 0.510 & 0.96 & $\begin{array}{l}0.87- \\
1.05\end{array}$ & 0.330 \\
\hline $\mathrm{pH}($ per 1) & 0.10 & $\begin{array}{l}0.01- \\
1.11\end{array}$ & 0.061 & 0.07 & $\begin{array}{l}0.01- \\
0.76\end{array}$ & 0.029 \\
\hline Potassium (per $1 \mathrm{mEq} / \mathrm{L}$ ) & 1.45 & $\begin{array}{l}1.02- \\
2.07\end{array}$ & 0.039 & 1.36 & $\begin{array}{l}1.00- \\
1.85\end{array}$ & 0.048 \\
\hline DIC score (per 1) & 1.83 & $\begin{array}{l}1.24- \\
2.69\end{array}$ & 0.002 & 1.54 & $\begin{array}{l}1.13- \\
2.10\end{array}$ & 0.006 \\
\hline
\end{tabular}


Table 5.

Results of a multiple linear regression analysis for factors associated with the length of hospital stay

\begin{tabular}{|c|c|c|c|c|c|c|c|c|}
\hline & \multicolumn{4}{|c|}{ Model without imputation $(\mathrm{N}=281)$} & \multicolumn{4}{|c|}{ Model with imputation $(\mathrm{N}=362)$} \\
\hline & \multirow{2}{*}{$\begin{array}{l}\text { Partial } \\
\text { regression } \\
\text { coefficient } \\
\beta\end{array}$} & \multicolumn{3}{|l|}{$95 \% \mathrm{Cl}$} & \multirow{2}{*}{$\begin{array}{l}\text { Partial } \\
\text { regression } \\
\text { coefficient } \\
\beta\end{array}$} & \multicolumn{3}{|l|}{$95 \% \mathrm{Cl}$} \\
\hline & & Lower & Upper & $\begin{array}{l}\mathrm{P}- \\
\text { value }\end{array}$ & & Lower & Upper & $\begin{array}{l}\mathrm{P}- \\
\text { value }\end{array}$ \\
\hline Age, years & 0.04 & -0.16 & 0.24 & 0.705 & 0.02 & -0.15 & 0.19 & 0.845 \\
\hline $\begin{array}{l}\text { Frailty (CFS } \geq \\
5)\end{array}$ & 5.22 & -1.41 & 11.84 & 0.122 & 3.81 & -1.78 & 9.39 & 0.181 \\
\hline \multicolumn{9}{|l|}{ Location } \\
\hline Outdoor & Reference & & & - & Reference & & & - \\
\hline Indoor & 8.75 & 1.45 & 16.06 & 0.019 & 7.19 & 1.14 & 13.24 & 0.020 \\
\hline \multicolumn{9}{|l|}{$\begin{array}{l}\text { Mechanism } \\
\text { causing } \\
\text { hypothermia }\end{array}$} \\
\hline $\begin{array}{l}\text { Acute medical } \\
\text { illness }\end{array}$ & Reference & & & - & Reference & & & - \\
\hline $\begin{array}{l}\text { Trauma, } \\
\text { Subimmersion, } \\
\text { and distress }\end{array}$ & 5.77 & -2.91 & 14.46 & 0.192 & 3.31 & -3.70 & 10.31 & 0.354 \\
\hline $\begin{array}{l}\text { Alcohol } \\
\text { intoxication }\end{array}$ & -8.95 & -20.82 & 2.91 & 0.139 & -10.82 & -20.92 & -0.71 & 0.036 \\
\hline $\begin{array}{l}\text { Others } \\
\text { (Unknown, } \\
\text { drug) }\end{array}$ & 1.39 & -5.09 & 7.88 & 0.673 & -0.29 & -5.96 & 5.37 & 0.919 \\
\hline $\begin{array}{l}\text { Temperature } \\
\left(\text { per } 1^{\circ} \mathrm{C}\right)\end{array}$ & -0.56 & -1.45 & 0.34 & 0.222 & -0.54 & -1.30 & 0.22 & 0.166 \\
\hline $\mathrm{pH}($ per 1) & -12.65 & -30.11 & 4.80 & 0.155 & -15.63 & -31.98 & 0.72 & 0.061 \\
\hline $\begin{array}{l}\text { Potassium (per } \\
1 \mathrm{mEq} / \mathrm{L})\end{array}$ & 0.64 & -1.83 & 3.10 & 0.611 & 0.55 & -1.67 & 2.77 & 0.629 \\
\hline $\begin{array}{l}\text { DIC score (per } \\
\text { 1) }\end{array}$ & 4.07 & 1.08 & 7.07 & 0.008 & 2.84 & 0.41 & 5.28 & 0.022 \\
\hline
\end{tabular}

$\mathrm{Cl}$, confidence interval; DIC, disseminated intravascular coagulopathy; ED, emergency department

\section{Figures}




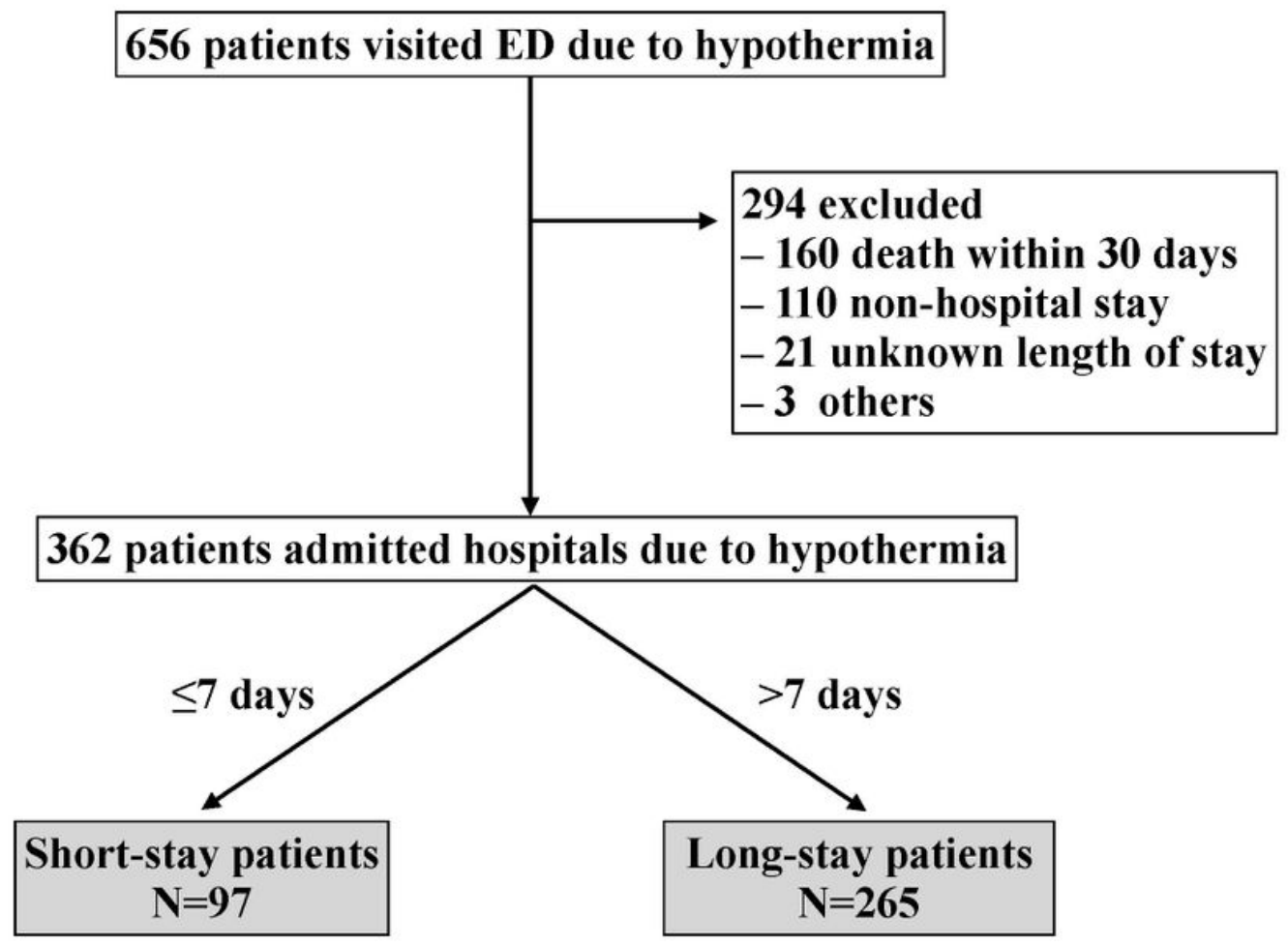

Figure 1

Study flowchart. ED, emergency department

\section{Supplementary Files}

This is a list of supplementary files associated with this preprint. Click to download.

- SuppFigure120200915.pdf 